\title{
JeF5e Noise in the Intensive Care Unit: fiction or fact?
}

\section{E. Claes, S. Vanwing, B. Stessel, A. Van Assche, L. Jamaer, J. Dubois}

Jessa Ziekenhuis, Anesthesia \& Intensive Care, Hasselt, Belgium

\section{Introduction:}

Noise exposure in the intensive care unit can have a negative impact on patients' well-being as well as on optimal functioning of both nursing and medical staff.

The WHO recommends average sound levels for hospital wards below $35 \mathrm{dBA}$ with a maximum of $40 \mathrm{dBA}$ at night time (I).

Reported sound levels in Intensive Care Units are significantly higher with average sound levels always exceeding $45 \mathrm{dBA}$ and for $50 \%$ of the time exceeding $52 \mathrm{dBA}(2)$.

After several patient complaints and remarks from the nursing staff as well as the medical staff about noise, we wanted to assess a potential noise problem by measuring sound levels in one ward (I2 beds) of our ICU.

\section{Methods:}

A sound level meter (Amptec I0EaZy RT) was placed bedside in a two-bed room as well as at the nursing station. Measurements were performed after a two week adjustment period to avoid a Hawthorne effect. Sound levels were continuously recorded for $24 \mathrm{hrs}$ at each location.

\section{Results:}

Bedside, average sound levels were $52.8 \mathrm{dBA}$ during the night and $54.6 \mathrm{dBA}$ during the day. Fourteen sound peaks above $80 \mathrm{dBA}$ were recorded with the highest peak at $10 \mathrm{I} .1 \mathrm{dBA}$.

At the nursing station, average soundlevels of $52.6 \mathrm{dBA}$ at night time and $53.9 \mathrm{dBA}$ at day time were recorded. Here, we noticed II peaks above $80 \mathrm{dBA}$ with a maximum sound peak of $90.6 \mathrm{dBA}$.

Those measurements are significantly above the WHO recommendations of $35 \mathrm{dBA}_{\mathrm{LAeq}}$ and $40 \mathrm{dBA}_{\mathrm{LAmax}}$, but comparable with other ICU recordings

\begin{tabular}{|l|l|l|l|l|}
\hline \multirow{2}{*}{ Average sound level: night } & \multicolumn{2}{|c|}{ Bedside } & \multicolumn{2}{c|}{ Nursing station } \\
\cline { 2 - 5 } & \multicolumn{1}{|c|}{ Before } & \multicolumn{1}{c|}{ After } & \multicolumn{1}{c|}{ Before } & \multicolumn{1}{c|}{ After } \\
\hline Average sound level: day & $52.8 \mathrm{dBA}$ & $52.9 \mathrm{dBA}$ & $52.6 \mathrm{dBA}$ & $52.2 \mathrm{dBA}$ \\
\hline Average sound level/24 hrs & $54.6 \mathrm{dBA}$ & $53.7 \mathrm{dBA}$ & $53.9 \mathrm{dBA}$ & $53.2 \mathrm{dBA}$ \\
\hline $\begin{array}{l}\text { Incidence sound level peak }>\mathbf{8 0} \\
\text { dBA }\end{array}$ & $53.7 \mathrm{dBA}$ & $53.3 \mathrm{dBA}$ & $53.3 \mathrm{dBA}$ & $52.7 \mathrm{dBA}$ \\
\hline Maximum sound level peak / 24 hrs & 14 & 16 & 11 & 10 \\
\hline
\end{tabular}

\section{Conclusion:}

The sound levels in our ICU clearly exceeded the WHO recommendations but are comparable with sound levels in other ICU's (I-2).

Those elevated sound levels as well as frequent sound level peaks can be responsible for the subjective feeling of noise pollution experienced by patients, nurses and doctors.

In our department, measures should be taken to reduce the average sound level on one hand and the incidence and altitude of sound level peaks on the other hand.

\section{References:}

I. Berglund B, Lindvall T, Schwela DH: Guidelines for Community Noise Geneva:

World Health Organization; 1999 [http://whqlibdoc.who.int/hq/I999/a68672.pdf].

2. Darbyshire and Young Critical Care 2013, I7:RI87 